\title{
Predictive Saccade Target Selection in Superior Colliculus during Visual Search
}

\author{
Kelly Shen ${ }^{1}$ and Martin Paré1,2,3 \\ ${ }^{1}$ Centre for Neuroscience Studies and Departments of ${ }^{2}$ Biomedical and Molecular Sciences and ${ }^{3}$ Psychology, Queen's University, Kingston, Ontario, Canada \\ K7L 3N6
}

Searching for a visual object naturally involves sequences of gaze fixations, during which the current foveal image is analyzed and the next object to inspect is selected as a saccade target. Fixation durations during such sequences are short, suggesting that saccades may be concurrently processed. Therefore, the selection of the next saccade target may occur before the current saccade target is acquired. To test this hypothesis, we trained four female rhesus monkeys (Macaca mulatta) to perform a multiple-fixation visual conjunction search task. We simultaneously recorded the activity of sensorimotor neurons in the midbrain superior colliculus (SC) in two monkeys. In this task, monkeys made multiple fixations before foveating the target. Fixation durations were significantly shorter than the latency of the initial responses to the search display, with approximately one-quarter being shorter than the shortest response latencies. The time at which SC sensorimotor activity discriminated the target from distracters occurred significantly earlier for the selection of subsequent fixations than for the selection of the first fixation. Target selection during subsequent fixations occurred even before the visual afferent delay in more than half of the neuronal sample, suggesting that the process of selection can encompass at least two future saccade targets. This predictive selection was present even when differences in saccade latencies were taken into account. Altogether, these findings demonstrate how neural representations on the visual salience map are processed in parallel, thus facilitating visual search.

Key words: concurrent processing; monkey; saccade target selection; visual search

\section{Introduction}

Active vision entails sequences of multiple fixations and saccadic eye movements (Henderson, 2003). During fixations, the foveal image is analyzed and the next saccade target is selected. This process is thought to occur within the visual salience map, wherein multiple stimulus representations compete for selection. Neurons within the frontal eye fields (FEF), the superior colliculus (SC), and the lateral intraparietal (LIP) area are thought to instantiate the visual salience map. Evidence from visual search studies show how these neurons initially have indiscriminate responses to stimuli in their receptive fields (RFs), but their activity evolves to indicate the target location before saccades (FEF: Thompson et al., 1996, 2005; SC: McPeek and Keller, 2002a; Shen and Paré, 2007; Shen et al., 2011; LIP: Ipata et al., 2006; Thomas and Paré, 2007). However, this account is limited to the selection of the first saccade target after display presentation. How these selection mechanisms extend beyond the first saccade remains mostly unknown.

The unconstrained nature of active vision makes the study of its underlying neural mechanisms using natural scenes difficult:

\footnotetext{
Received Sept. 10, 2013; revised March 3, 2014; accepted March 7, 2014.

Author contributions: K.S. and M.P. designed research; K.S. performed research; K.S. analyzed data; K.S. and M.P. wrote the paper.

This research was supported by Canadian Institutes of Health Research Grant MOP 38089 and Queen's University (M.P.). K.S. held a postgraduate scholarship from the Natural Sciences and Engineering Council of Canada.

Correspondence should be addressed to Martin Paré, Department of Biomedical and Molecular Sciences, Queen's

University, Kingston, Ontario, Canada K7L 3N6. E-mail: martin.pare@queensu.ca.

K. Shen's present address: Rotman Research Institute, Baycrest, Toronto, Ontario, Canada M6A 2E1.

DOI:10.1523/JNEUROSCI.3880-13.2014

Copyright $\odot 2014$ the authors $\quad 0270-6474 / 14 / 345640-09 \$ 15.00 / 0$
}

visual stimulation is highly variable across fixations and saccades with similar vectors occur infrequently (Phillips and Segraves, 2010). Difficult search tasks offer an alternative approach because they naturally promote multiple fixations (Motter and Belky, 1998; Shen and Paré, 2006; Nothdurft et al., 2009). Combined with neuronal recordings, search tasks can be used to investigate saccade target selection from time-varying visual representations during sequences of fixations (Bichot et al., 2005; Zhou and Desimone, 2011).

Interestingly, in multi-fixation search, fixation durations that occur after the initial saccade response can be shorter than the latency of the initial response (Viviani and Swensson, 1982; McPeek and Keller, 2001; Van Loon et al., 2002). Similarly, brief intersaccadic intervals have been reported in reading and simple saccade tasks (for review, see Bahill et al., 1975; Rayner, 1998). Short intersaccadic intervals are characteristic of preplanned sequences (Becker and Jürgens, 1979; Zingale and Kowler, 1987) and thought to reflect concurrent saccade processing. Indeed, information about a search target may be acquired at least one fixation ahead. The second saccade of a sequence is influenced by visual information available before the first saccade (Caspi et al., 2004). Observers can identify a search target at least one fixation in advance (Kotowicz et al., 2010), and planning can occur for sequences of up to three saccades (De Vries et al., 2013). Moreover, visual discrimination is enhanced at the locations of future saccade targets before the first saccade (Godijn and Theeuwes, 2003; Baldauf and Deubel, 2008; Gersch et al., 2009), suggesting that visual attention can be allocated in parallel more than one fixation ahead. 


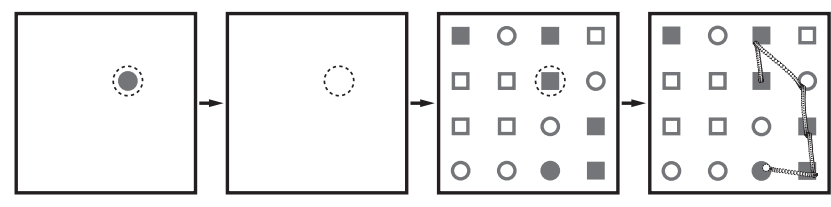

Figure 1. Grid conjunction search task. Trial progression and example fixation sequence. Each trial began with the monkey fixating on a stimulus that acted as a cue for the target. A gap period ( $200 \mathrm{~ms}$ ) followed during which the monkey had to maintain fixation. When the search display was presented, monkeys were free to search for the unique target among 15 distracters and were rewarded only after they fixated the target. An example fixation sequence is depicted in the rightmost panel. Eye position is denoted by the dashed circle.

Because saccade target selection is thought to rest on the allocation of visual attention, the process of selecting the next saccade target could begin before the current saccade target is acquired. We tested this hypothesis by recording the activity of SC visuomovement neurons while monkeys searched for a target defined by a unique conjunction of features.

\section{Materials and Methods}

Data were collected from four female rhesus monkeys (Macaca mulatta, 5-6.5 kg, 6-10 years old) cared for under experimental protocols approved by the Queen's University Animal Care Committee and in accordance with the Canadian Council on Animal Care guidelines. During the postsurgical recovery period, animals received both antibiotics and analgesic medications. Monkeys were then trained with operant conditioning and positive reinforcement to perform fixation and saccade tasks for a liquid reward until satiation. The surgical procedure, stimulus presentation, data acquisition, and data analyses have been described previously (Shen and Paré, 2006, 2007).

\section{Behavioral paradigms}

Grid conjunction search task. The main data of this report were collected while monkeys performed an unconstrained grid conjunction search task. On each trial, monkeys fixated a fixation stimulus that served as a cue for the target. This fixation stimulus could randomly appear in any of the 16 possible positions for the subsequent grid display (Fig. 1). Once fixated for $500-800 \mathrm{~ms}$, the fixation stimulus disappeared, followed by a gap period of $200 \mathrm{~ms}$ during which there was no visual stimulation, but the animal was required to maintain fixation within a defined window. The search display then appeared, consisting of 16 stimuli that were conjunctions of a color [yellow: CIE (for Commission internationale de l'éclairage) $x=0.43$, CIE $y=0.48$; or green: CIE $x=0.29$, CIE $y=0.60$ ] and a shape (circle or square). The single target stimulus was a unique combination of these features, with distracter stimuli that could share either a feature with the target (same color or same shape) or have no feature in common with the target (opposite). The distracter types appeared in equal proportions (i.e., five each). The stimuli were matched for luminance $\left(20 \mathrm{~cd} / \mathrm{m}^{2}\right)$ using a Minolta CS-100 Plus photometer and presented on a black background $\left(<0.01 \mathrm{~cd} / \mathrm{m}^{2}\right)$. Monkeys were given $500 \mathrm{~ms}$ after the presentation of the search display to make their first gaze fixation and were given an additional $5000 \mathrm{~ms}$ for subsequent fixations if this initial fixation was not on the target. Monkeys were required to fixate the target for $500 \mathrm{~ms}$ to receive a liquid reward. The search target remained the same within each experimental session but changed across sessions. For sessions in which only behavioral data were collected, the stimuli were each $1^{\circ}$ in diameter and were spaced $10^{\circ}$ apart horizontally and vertically. For sessions in which neuronal activity was also recorded, the stimuli were arranged such that their spacing was determined by the vector of the RF of the neuron. In other words, the search display was positioned so as to maximize the probability that a stimulus fell in the RF of the neuron on each fixation. The stimulus dimensions were then scaled with the eccentricity of the RF and in proportion to striate cortex RF magnification (Van Essen et al., 1984). Behavioral data were collected from all four animals (monkey F, 8; monkey M, 24; monkey G, 4; monkey $\mathrm{H}, 4$ ). In two of the animals (monkeys $\mathrm{M}$ and $\mathrm{F}$ ), we also simultaneously recorded the extracellular activity of single SC neurons $(n=32)$ using previously described methods (Paré and Wurtz, 2001). Spike occurrences were sampled at $1 \mathrm{kHz}$.

Grid detection task. Each grid conjunction search session was preceded by a grid detection task that served to familiarize the monkey with the target for that session. Trials in this task proceeded as those in the search task, but on display presentation only the target stimulus appeared (with no distracters) and monkeys were rewarded for fixating the single target stimulus within $500 \mathrm{~ms}$ of presentation. In neuronal recording sessions, this task was also used to characterize the extent of the RF of the neuron and to ensure proper display alignment for the grid conjunction search task.

Concentric conjunction search task. This report also includes neuronal data recorded from monkeys $\mathrm{G}(n=9)$ and $\mathrm{H}(n=11)$ using an unconstrained conjunction search task that was the focus of a previous study (Shen and Paré, 2007). In this task, each trial began with a central fixation stimulus that was identical to the target stimulus. After the fixation interval (500-800 ms), a concentric array of one target and seven distracter stimuli (see Fig. 7A) appeared simultaneously with the disappearance of the fixation stimulus. Monkeys were allowed $500 \mathrm{~ms}$ to make their first fixation on the array. If the target was successfully foveated on this first fixation, the animals received a maximal liquid reward amount along with a reinforcement tone. If the first fixation was on a distracter stimulus, animals were allowed an additional $2000 \mathrm{~ms}$ to fixate the target, and a minimal amount $(<0.33$ of the maximal amount) of liquid reward was delivered along with the reinforcement tone. Stimuli were conjunctions of a color (red or green) and a shape (circle or square). One stimulus was placed in the RF of the neuron, whereas all other stimuli were positioned equidistantly from it and each other.

Concentric detection task. A detection task preceded each concentric conjunction search session to familiarize monkeys with the search target of the session, as well as to delineate the extent of the RF of the neuron. The task proceeded as in the concentric conjunction search task, but only the target appeared with the disappearance of the fixation cue.

Delayed saccade task. In all recording sessions, the responses of neurons were first characterized while monkeys performed a delayed saccade task to temporally dissociate visual stimulation from saccade execution (Paré and Wurtz, 2001). Data collected in this task were used to calculate the visual onset latencies of our neuronal sample and to describe the visuo-movement properties of each neuron (Table 1). This task served to additionally characterize the extent of the RF of each neuron.

\section{Data analysis}

Methods for neuronal data analysis have been described previously (Thompson et al., 1996; Shen and Paré, 2007; Thomas and Paré, 2007). Briefly, neuronal activity was quantified as continuously varying spike density functions aligned on the onset of the visual display presentation (stimulus-aligned), fixations after the first saccade (fixation-aligned), or saccades (saccade-aligned). Spike density functions were constructed by convolving spike trains with a combination of growth (1 ms time constant) and decay (20 ms time constant) exponential functions that resembled a postsynaptic potential (Thompson et al., 1996). To be included in any analysis, neurons had to contribute at least five trials in each condition of interest.

Visual onset latency (Table 1) was taken as the time at which the activation function reached a threshold ( mean $_{\text {baseline }}+2 \times \mathrm{SD}_{\text {baseline }}$ ) and remained above that threshold for 50 consecutive ms after stimulus onset in the delayed saccade task. Baseline activity was computed as the average activity during the last $100 \mathrm{~ms}$ before stimulus onset, and updated every millisecond thereafter if the activity remained below the currently determined threshold. For neurons having little to no baseline activity $(<5$ spikes/s), thresholds were arbitrarily set at 5 spikes/s.

The extent of the RF of each neuron was determined using detection tasks to ensure that only one stimulus in the search display yielded a maximum visual response. Visual responses in these tasks were computed as the mean response during a 25 ms epoch after visual response onset. In the grid detection task, all stimulus positions outside of what was considered the RF position yielded visual responses $<50 \%$ of the maximal $R F$ response. Figure $3 C$ shows the visual tuning properties of an 
Table 1. Discharge properties in the delayed saccade task for neurons subsequently recorded using the grid conjunction and concentric conjunction search tasks

\begin{tabular}{|c|c|c|c|c|c|c|}
\hline Search & $n$ & $\begin{array}{l}\text { Visual onset } \\
\text { latency (ms) }\end{array}$ & vis (spikes/s) & $\begin{array}{l}\text { Delay activity } \\
\text { (spikes/s) }\end{array}$ & $\begin{array}{l}\text { mov } \\
\text { (spikes/s) }\end{array}$ & VMI \\
\hline Grid & 32 (monkey M, 24; monkey F, 8) & $41 \pm 1(32-57)$ & $50 \pm 7(1-171)$ & $23 \pm 5(0-112)$ & $288 \pm 28(43-651)$ & $-0.64 \pm 0.05(-0.99$ to 0.01$)$ \\
\hline Concentric & 20 (monkey G, 9; monkey H, 11) & $42 \pm 2(30-63)$ & $67 \pm 11(14-231)$ & $38 \pm 7(1-123)$ & $359 \pm 41(42-625)$ & $-0.64 \pm 0.06(-0.90$ to -0.03$)$ \\
\hline
\end{tabular}

Visual onset latency, delay period activity, vis, mov, and VMI are as described in Materials and Methods [mean \pm SEM (range)].

example neuron during this task. Figure $7 C$ shows the visual tuning properties of an example neuron during the concentric detection task.

We used signal detection theory to quantify the process of saccade target selection in our search task (Thompson et al., 1996; Shen and Paré, 2007; Thomas and Paré, 2007). This method estimates how well an ideal observer of SC activity can discriminate between the activity related to a target falling in the RF of the neuron and that related to a distracter in the $\mathrm{RF}$ of the neuron. Receiver operating characteristic (ROC) curves were calculated during successive $5 \mathrm{~ms}$ intervals, and the area under each of those ROC curves was then plotted as a function of time and fit with a Weibull function to describe the time course of saccade target selection. The point at which the function reached a criterion value of 0.75 was taken as the discrimination time (DT) of the neuron, and the upper asymptote of the function was taken as the discrimination magnitude (DM) of the neuron. Best-fit functions were calculated only with activity occurring before the initiation of saccades, and calculations were terminated once there were fewer than five target or distracter trials. We also conducted successive rank-sum tests on the same $5 \mathrm{~ms}$ intervals used for the ROC analysis to determine whether target- and distracter-related activity were significantly different from each other (Thomas and Paré, 2007). For both the rank-sum tests and the ROC analysis, the ranges of saccade latencies in target and distracter trials were matched. The minimum saccade latency in response to display onset was fixed to $90 \mathrm{~ms}$. Fixations were only included if the preceding saccades were made away from the RF (five opposing directions) of the neuron.

To calculate DT/response time (RT) slopes, we divided the trials for each neuron into short and long RT groups and determined the DT for each group. We did this for both single- and multiple-fixation trials. We then determined the slope of the relationship between DT and RT. A slope of 1 would indicate that DT is predictive of RT and that the trialto-trial variability in RT may be related to differences in visual processing rather than movement programming. Alternatively, a slope of 0 indicates that DT is fixed despite variability in RT and that trial-to-trial variability in RT may be more related to differences in movement programming (Thompson et al., 1996; Shen et al., 2011).

All 52 neurons were recorded within the SC intermediate layers and identified as visuo-movement neurons using data collected in the delayed saccade task. Their activity before saccades (last $100 \mathrm{~ms}$ before saccade onset; Table 1) was significantly greater (rank-sum test, $p<$ 0.001 ) than the corresponding delay activity (last $300 \mathrm{~ms}$ epoch before fixation stimulus disappearance), and they had reliable visually evoked responses within $100 \mathrm{~ms}$ of display onset. We calculated a visuomovement index (VMI; Shen et al., 2011) with data collected in the delayed saccade task (Table 1). This index quantifies the relative magnitude of visually evoked and saccade-related activity of each neuron: $\mathrm{VMI}=(\mathrm{vis}-\mathrm{mov}) /(\mathrm{vis}+\mathrm{mov})$, where vis is the mean discharge rate over the first $100 \mathrm{~ms}$ after stimulus presentation, and mov is the peak discharge rate within $\pm 40 \mathrm{~ms}$ of saccade onset. Neurons with stronger visually evoked activity have VMIs closer to 1.0, and those with stronger saccade related activity have VMIs closer to -1.0 .

\section{Results}

We collected data from four monkeys over 40 sessions of the grid conjunction search task for a total of 27,747 trials. Monkeys acquired the search target successfully with a single fixation in only $29.7 \%$ of trials. Because the fixation stimulus could randomly appear in any of the 16 locations within the grid, the distance between the target and fixation stimuli could vary. As a result, the probability of acquiring the target after a single fixation was significantly greater when the target was located adjacent to the fixation stimulus than when it was further eccentric $(0.31 \pm 0.01$ vs $0.26 \pm 0.01 ; p<0.01, t$ test $)$. These results suggest that stimuli were discriminable and that discriminability decreased somewhat with eccentricity. On average, the monkeys needed $2.7 \pm$ 0.26 (range, 1-14) fixations per trial to acquire the target. This was significantly less than that expected by random scanning $(2.7$ vs $7.5 ; p<0.0001, t$ test), which suggests that search was guided by the visual array composition, i.e., monkeys did not adopt an idiosyncratic, systematic scanning strategy.

The time it took to respond to the initial presentation of the visual search display (RT) was not different for trials in which monkeys made a single fixation compared with trials in which they made a sequence of multiple fixations ( $188 \pm 3$ vs $184 \pm 2$ $\mathrm{ms} ; p=0.23, t$ test). RT in multiple-fixation trials was significantly longer than the durations of the subsequent fixations in all four animals (Fig. $2 A ; p<0.001, t$ test). Figure $2 B$ shows how, in a single session for one animal (monkey $F$ ), this effect was attributable to a proportion (25\%) of fixation durations that were shorter than the shortest RT. This was also the case for the other monkeys: on average, $26 \pm 2 \%$ (monkey F, 36\%; monkey $\mathrm{M}$, $19 \%$; monkey G, 32\%; monkey $\mathrm{H}, 45 \%$ ) of subsequent fixations had durations shorter than the shortest initial RT, which was on average $116 \pm 2 \mathrm{~ms}$ (Fig. 2C). These behavioral data suggest that the process of saccade target selection can occur in parallel for at least two saccade targets. Moreover, fixation durations decreased significantly as a function of fixation number for trials having one to four fixations before target foveation (Fig. $2 D$; all $p<0.05$, oneway ANOVA). A post hoc Bonferroni's pairwise analysis revealed that the final fixation just before target foveation was significantly shorter $(p<0.05)$ than all previous fixation durations in all four trial types. These data additionally suggest that information about target location accumulated over the course of each trial.

To determine whether this parallel selection occurs at the level of the visual salience map, we simultaneously recorded the activity of 32 single SC visuo-movement neurons in two monkeys while they performed the grid conjunction search task. We quantified the process of saccade target selection using signal detection theory (see Materials and Methods) and determined the discrimination probability over time with data aligned to stimulus (search display) onset. All neurons discriminated the target from distracters before saccades were made. On average, DT was $139 \pm$ $3 \mathrm{~ms}$ (range, 106-174 ms) after the onset of the search display, and DM was $0.94 \pm 0.01$ (range, $0.79-1$ ) for trials in which the target was acquired with a single fixation. Using successive ranksum tests to determine DT produced similar results: all neurons had significantly greater target than distracter activity $(p<0.05)$ before saccades, with DT occurring on average $130 \pm 4 \mathrm{~ms}$ (range, 97-187 ms) after stimulus onset.

To examine the process of saccade target selection during subsequent fixations, we compared the above single-fixation trials to ones in which the monkey made multiple fixations before acquiring the target (Fig. $3 A, B$, insets). Figure 3 illustrates this comparison for one example neuron. In single-fixation trials, this neuron discriminated the target from distracters $126 \mathrm{~ms}$ after the onset of the search display (Fig. 3A). In multiple-fixation trials, DT was 98 
A

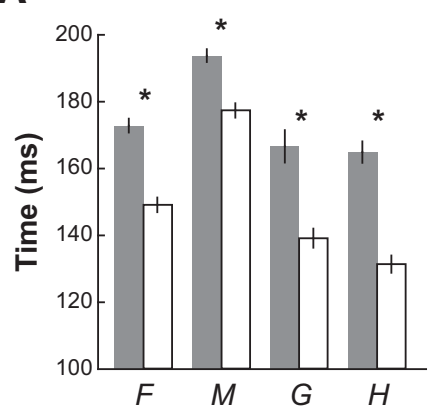

B

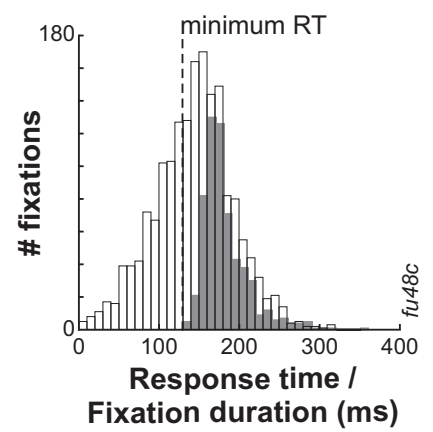

C

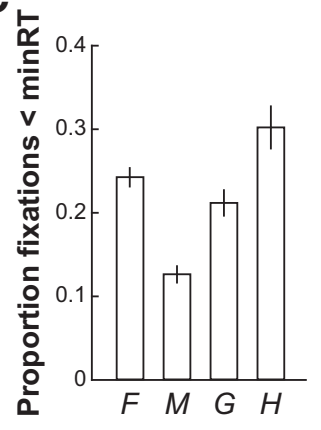

D

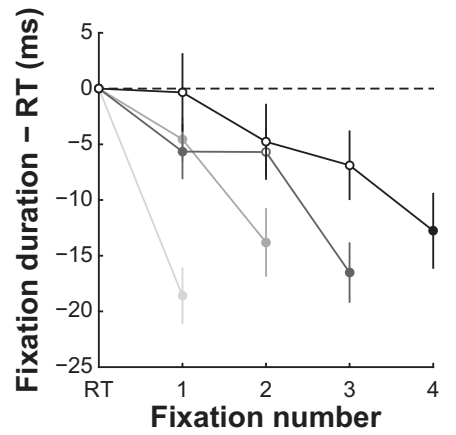

Figure 2. Search task behavior. $\boldsymbol{A}$, Average \pm SE initial RTs (filled bars) and fixation durations (open bars) in multiple saccade trials for each monkey. ${ }^{*} p<0.001 . B$, Example session data from monkey F. Initial RT (filled bars) and fixation duration (open bars) distributions for all distracters. Minimum RT in this example session was 119 ms. $C$, Mean \pm SE proportion of total fixations with durations less than the minimum RT for each monkey. Ranges: monkey F, 28-44\%; monkey M, 7-36\%; monkey G, 27-36\%; monkey H, 38-54\%. D, Average \pm SEM difference across monkeys between fixation duration and initial RT as a function of trial progression for trials having 1, 2, 3 and 4 fixations before target foveation. There was a significant decrease in fixation duration as a function of trial progression in all four trial types ( $p<0.05$, one-way ANOVA). Filled circles indicate times at which the fixation duration was significantly shorter than the previous fixation ( $p<$ 0.05 , Bonferroni's correction).

A

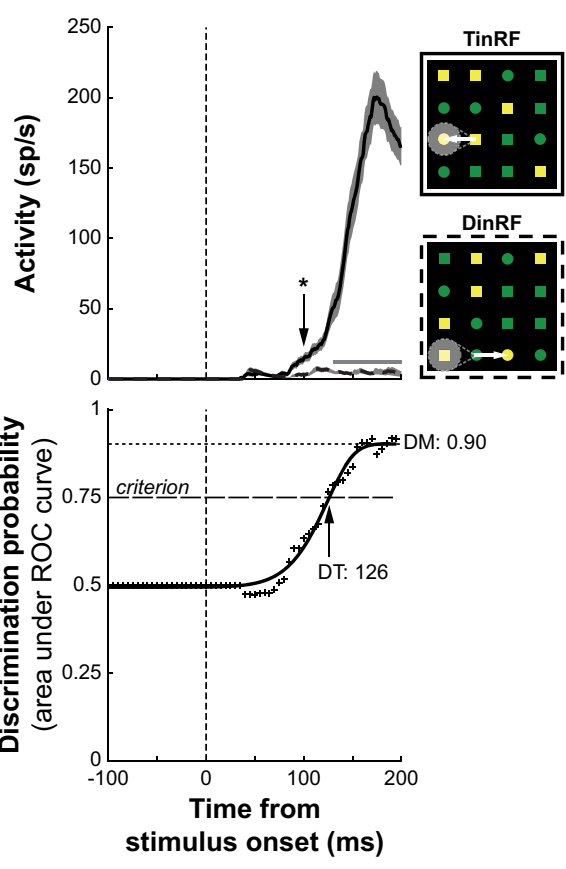

B

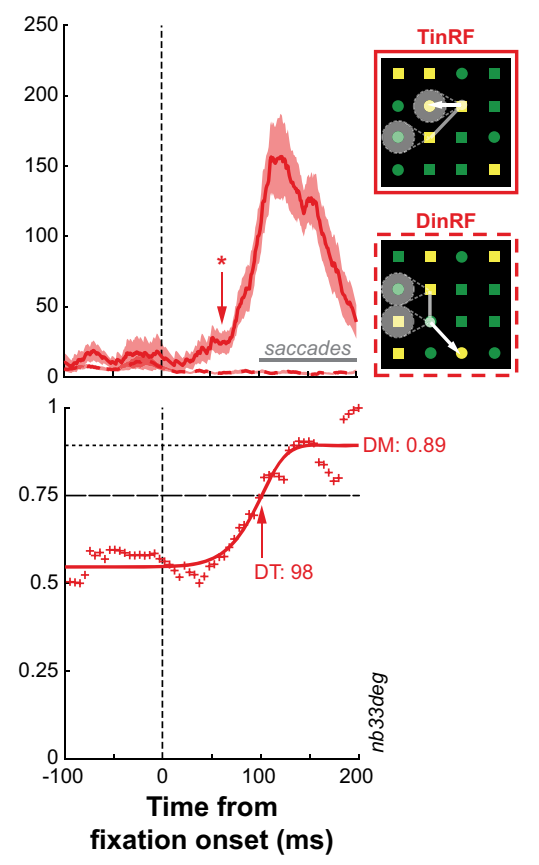

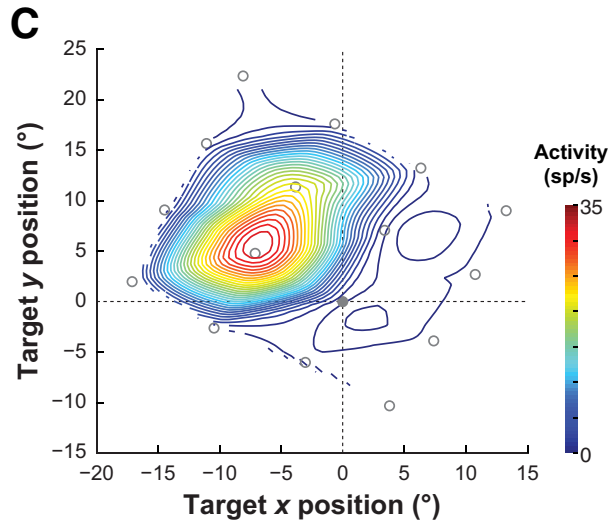

Figure 3. Example SC sensorimotor neuron activity in the grid conjunction search task. $\boldsymbol{A}$, Saccade target selection in single-saccade trials. Top, Mean \pm SE activity for target (TinRF) (solid) and distracter (DinRF) (dashed) trials, aligned to the onset of the visual search display. The occurrence of saccades is indicated by the gray horizontal lines. * denotes the time of significantly greater target-related activity ( $p<0.05$, successive rank-sum tests). Bottom, Discrimination probability as a function of time. The areas under the ROC curve ( + ) were fit with a Weibull function, and DT was determined using an arbitrary criterion of 0.75 . DM was determined by the upper asymptote of the Weibull function. $\boldsymbol{B}$, Saccade target selection in multiple-saccade trials. $\boldsymbol{C}$, Contour plot of interpolated visual responses of the same example neuron in the grid detection task. Stimulus positions for the grid display denoted by open gray circles relative to eye position (filled gray circle).

ms after the onset of subsequent fixations (Fig. 3B). DMs in both single- and multiple-fixation trials were similar and near perfect $(\sim 0.9)$. Figure 4 depicts the normalized activity profile during single- and multiple-fixation trials for all neurons. The increase in normalized firing rate for target-related activity occurred much earlier in multiple- than single-fixation trials ( -40 vs 90 $\mathrm{ms})$. Interestingly, the increase in activity around fixation onset in multiple-fixation trials occurs only for the stimulus that will become the next saccade target. This was also the case for the individual activity profiles of all neurons.

We quantified the saccade target selection process for the population of neurons we recorded by calculating the mean $\pm \mathrm{SE}$ discrimination probability over time for both single- and multiple-fixation trials. The discrimination probability was already significantly greater at fixation onset for multiplefixation trials and remained that way until $145 \mathrm{~ms}$ after stimulus/fixation onset (Fig. $5 A ; p<0.05, t$ tests), suggesting that the selection of a saccade target that was part of a sequence occurred earlier than the selection of a single-saccade target. On average, DT was significantly shorter in multiple-fixation trials $(76 \pm 6 \mathrm{~ms})$ than in single-fixation trials $(139 \pm 3 \mathrm{~ms}$; $p<0.001$, paired $t$ test). Discrimination probabilities were not different between single- and multiple-fixation trials 60-100 ms before stimulus appearance (Fig. $5 A$, open circles; $p>0.05$, 

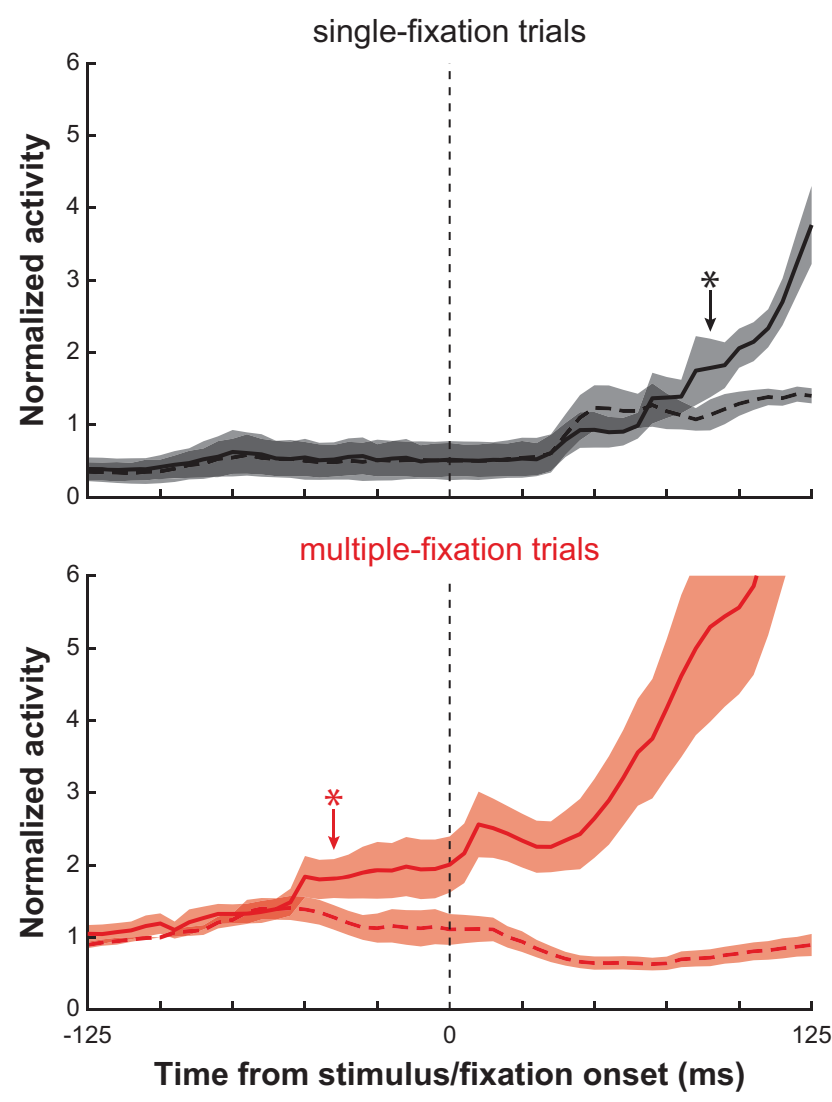

Figure 4. Population activity in the grid conjunction search task. Mean \pm SE normalized activity profile for all neurons aligned to the onset of fixation just before target acquisition for single-fixation (top) and multiple-fixation (bottom) trials. The target-related (solid) and distracter-related (dashed) activity of each neuron was normalized to its distracter-related activity in multiple-fixation trials at $-100 \mathrm{~ms}$ before fixation onset. * indicates the time at which target- and distracter-related activity became significantly different $(p<0.05, t$ tests).

$t$ test) and were also not different from chance $(p>0.05)$, indicating that the early selection of a subsequent saccade target was not attributable to any differences in neuronal activity occurring during the previous fixation.

With reference to the visual afferent delay, discrimination occurred only $34 \pm 6 \mathrm{~ms}$ (range, -51 to 101 ) after the onset of visually evoked responses (Fig. $5 B$ ), whereas it occurred nearly $100 \mathrm{~ms}$ later in single-fixation trials ( $98 \pm 3 \mathrm{~ms}$; range, 66-133). These findings were additionally supported by a temporal analysis of target and distracter activity. In single-fixation trials, the earliest time that target activity was significantly greater than distracter activity was $87 \mathrm{~ms}$ after the display onset (Fig. $5 \mathrm{~A}$, bottom). However, in multiple-fixation trials, more than half (18 of $32,56 \%)$ of the neurons had significantly greater $(p<0.05$, rank-sum test) target activity before the onset of their visually evoked responses; greater activity was also observed before fixation onset in $16 \%$ (5 of 32) of neurons.

It is possible that the shift toward an earlier selection process in multiple-fixation trials was driven mainly by fixations of very short duration (i.e., 50-100 ms). The earlier onset of movementrelated activity in these cases could have contributed to the observed shift to an earlier DT, regardless of the target selection process, when the data were aligned to fixation onset. To account for any differences in saccade timing between the single- and multiple-fixation trials, we performed the analysis again with the data aligned to the onset of saccades. We found that discrimina- tion probabilities were still significantly greater in multiplefixation trials up to $40 \mathrm{~ms}$ before saccades (Fig. $5 C$; $p<0.05, t$ tests). Even when the time of movement onset was accounted for, we found an earlier DT for multiple-fixation trials, suggesting that the predictive signals we observed were related to the selection process rather than purely to the programming of an eye movement.

To test whether our behavioral findings of information accrual (Fig. 2D) was supported by the underlying neural activity, we examined the average number of fixations made in each session and related it to DT calculated from multiple-fixation trials (i.e., calculated using the final fixation in the trial just before target foveation). We found that multiple-fixation DT was earliest for sessions that had more fixations per trial for both fixationaligned ( $r=-0.57 ; p<0.001$, Pearson's correlation) and saccade-aligned $(r=-0.35 ; p<0.05)$ data (Fig. $5 D)$. These data suggest that generally more information had accumulated over those sessions with longer trials, resulting in shorter DTs and fixation durations.

That the discrimination probabilities were not different just before saccades suggests that the ability of the neurons to discriminate the target stimulus from distracters did not change between the two conditions. McPeek and Keller (2002a) reported previously that DT in some SC visuo-movement neurons predicted saccade latencies in single-fixation visual search. Our observation that there was a shift to earlier DTs even when data were aligned on saccade onset might have occurred because of a change in this relationship between DT and RT in multiple-fixation trials. To test this hypothesis, we calculated DT/RT slopes for each neuron for both single- and multiple-fixation trials. There were sufficient data (at least five trials per condition) in 24 neurons for this analysis. On average, DT/RT slopes in single-saccade trials were $0.99 \pm 0.13$ and not significantly different from $1(p=0.93, t$ test), with DT leading RT by $65 \pm 4 \mathrm{~ms}$. DT/RT slopes for those same neurons in multiple-fixation trials were also not significantly different from $1(1.0 \pm 0.17 ; p=0.98)$, but the lead time was significantly longer than in single-fixation trials (92 $\pm 5 \mathrm{~ms}$; $p<0.0001$, paired $t$ test). Therefore, DT in multiple-fixation trials was equally predictive of RT, although it occurs earlier.

\section{Concentric conjunction search}

To determine whether the predictive selection of saccade targets can be observed in other visual search tasks as well as in other monkeys, we reanalyzed the activity of 20 SC visuo-movement neurons recorded in monkeys $\mathrm{G}$ and $\mathrm{H}$ during a concentric conjunction search task from our previous report (Shen and Paré, 2007). In this task, monkeys were allowed an extra $2000 \mathrm{~ms}$ to acquire the search target if their initial saccade landed on a distracter. On $\sim 30 \%$ of trials, they needed more than one fixation to acquire the target. In these trials, the duration of the first fixation was significantly shorter than the time to respond to display presentation (113 \pm 2 vs $155 \pm 1 \mathrm{~ms} ; p<0.0001, t$ test $)$. We examined SC neuronal activity on trials in which monkeys made a second corrective saccade to the target that had been brought into the RF of the neuron after the first saccade (Fig. 6A; Murthy et al., 2007). We compared these "target" trials to trials in which a distracter fell in the RF after the first saccade and the monkey made a correct second saccade to the target located outside of the new RF position of the neuron. There were sufficient data in 16 neurons for this analysis (monkey G, 8; monkey H, 8). An example neuron, depicted in Figure $6 B$, shows how DT in multiplefixation trials was at approximately its visual onset latency $(43 \mathrm{~ms}$ after search display onset) and occurred much earlier for the 


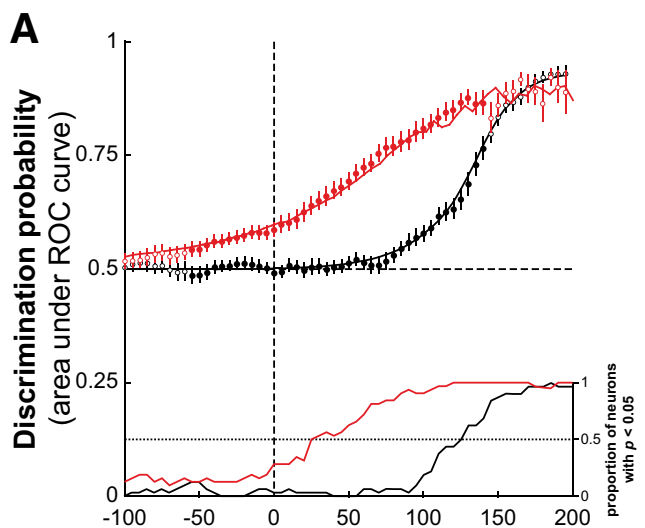

Time from stimulus/fixation onset (ms)
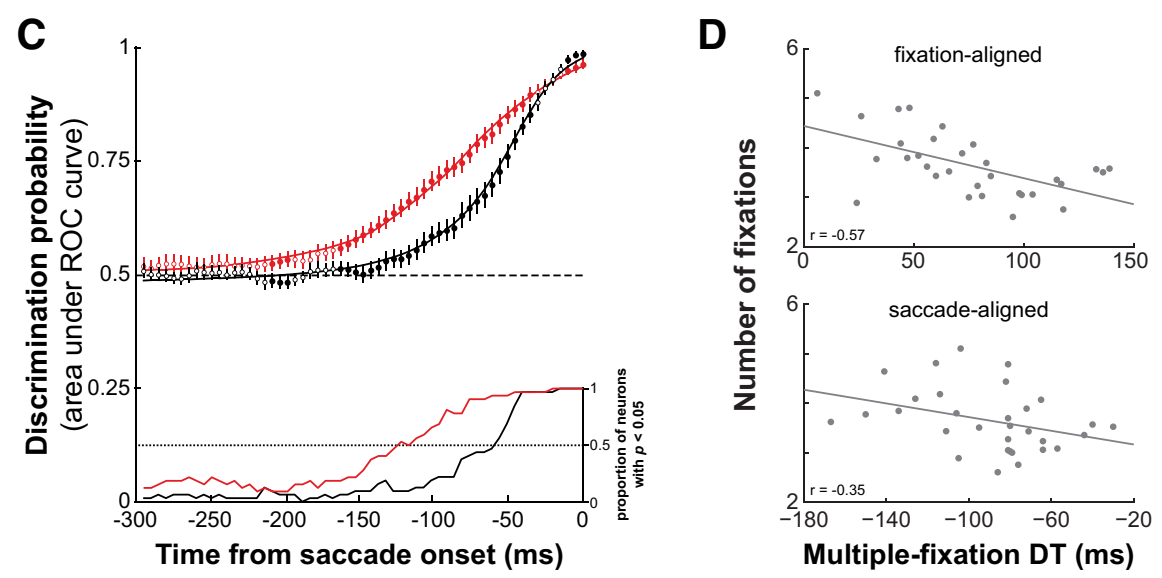

Figure 5. Predictive saccade target selection in SC, grid search task. $A$, Mean \pm SE discrimination probability as a function of time, aligned to the onset of the search display. Significantly different ( $p<0.05, t$ tests) discrimination probabilities between single- and multiple-fixation trials indicated by filled symbols. Inset, Proportion of neurons having significantly greater $(p<0.05$, rank-sum test) target- than distracter-related activity as a function of time. $\boldsymbol{B}$, Mean \pm SE DT relative to the visual afferent delay for single- and multiple-fixation trials. The visual afferent delay for each neuron was determined by its visual response onset latency in the delayed saccade task. Individual neuron DTs denoted by gray circles. $C$, Data as in $\boldsymbol{A}$, aligned to the onset of saccades. Black, Single-fixation trials; red, multiple-fixation trials. $\boldsymbol{D}$, Average number of fixations per trial as a function of multiple-fixation DT across sessions for data aligned to fixation onset (top) and saccade onset (bottom).

selection of the second saccade target than for the first. Across this neuronal sample, discrimination in multiple-fixation trials occurred on average $9 \pm 9 \mathrm{~ms}$ after the first fixation, whereas it occurred $109 \pm 4 \mathrm{~ms}(p<0.0001, t$ test; Fig. $6 C)$ after the onset of the search display in single-fixation trials. Therefore, these data replicate our findings of predictive saccade target selection in SC in a different paradigm with different animals.

In our previous report, we also showed how the target representation is enhanced even when it is not selected for the first saccade, i.e., SC neuronal activity signals stimulus identity (Shen and Paré, 2007). Given the evidence presented above for the concurrent selection of saccade targets in SC in our concentric array task, could this enhancement in activity actually be related to the stimulus (i.e., target) identity rather than to the selection of the second saccade target? We examined activity during a $25 \mathrm{~ms}$ epoch just before saccades in three conditions: target-related activity in two-fixation trials when the subsequent fixation duration was short and when the fixation duration was long, as well as distracter-related activity in single-fixation trials. We had sufficient data in all 20 neurons to perform this analysis. For the example neuron shown in Figure $7 A$, we found an enhancement of target-related activity before a subsequent fixation was made to that target. This enhancement was greater for the shortest fixation durations than for longer ones, consistent with previous findings in a feature search task (McPeek and Keller, 2002b). However, the targetrelated activity in our conjunction search task in the longest fixation duration trials was still greater than distracter-related activity. To quantify these effects across the sample, we calculated a stimulus identity index by normalizing the target-related activity of each neuron in the two conditions (short and long fixation duration) to its distracter-related activity (Fig. 7B). On average, the shortest fixation duration trials had an index greater than that for longduration trials $(1.9 \pm 0.1$ vs $1.6 \pm 0.1 ; p<$ $0.05, t$ test), suggesting that the enhancement in activity was related to the concurrent processing of two saccade targets. However, both target conditions were still significantly $>1$ (i.e., distracter-related activity; $p<0.0001, t$ tests), indicating that the signaling of stimulus identity is independent of the preceding fixation duration in the concentric conjunction search task.

\section{Relationship to discharge properties}

To determine whether the ability of an individual neuron to select a subsequent saccade target is predicted by its discharge properties, we tested for a relationship between both the DT and DM of a neuron in multiple-fixation trials and its discharge characteristics. Neither DT nor DM was correlated with the position of a neuron along the VMI $(p=0.50$ and $p=0.32$, respectively, Pearson's correlation). The same was true when DT and DM were tested against the magnitude of the visually evoked responses $(p=0.88$ and $p=0.90)$ and saccaderelated activity $(p=0.24$ and $p=0.20)$. Moreover, DT and DM were not predicted by the discharge rate of a neuron during the delay period of the delayed saccade task $(p=0.77$ and $p=0.52)$.

\section{Discussion}

We investigated saccade target selection while monkeys executed a multiple-fixation search for a target embedded in a structured search array. Consistent with previous behavioral studies, we found that fixation durations were significantly shorter than the latency of the initial responses to the search array. Accordingly, SC sensorimotor neurons displayed discriminating activity significantly earlier when the target was acquired after several fixations compared with when the target was fixated just after the search array onset. Discriminating activity occurred before the visual afferent delay in more than half of the neuronal sample. These predictive signals existed in addition to the representation of target identity in our conjunction search task. Our data demonstrate how neural representations on the visual salience map are not processed one fixation at a time and how advanced saccade target selection facilitates visual search.

Previous observations that fixation durations are shorter than initial RTs during visual search tasks were interpreted with the 
A
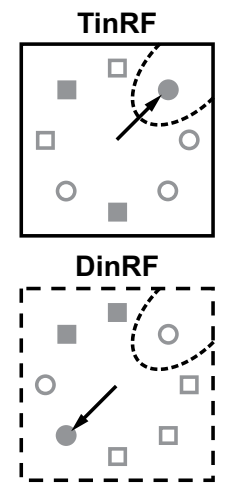

B
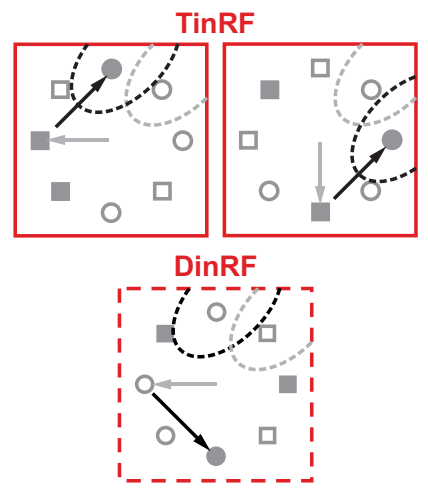

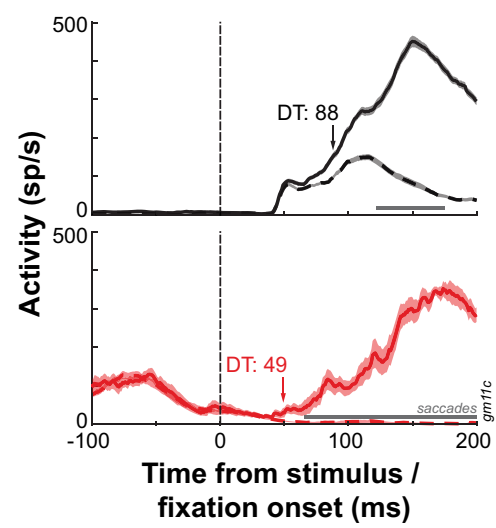

C

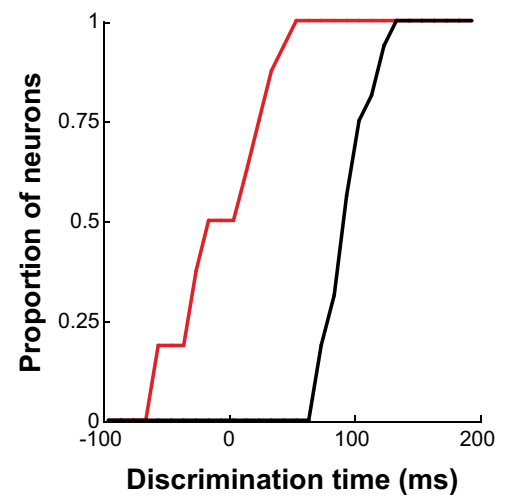

Figure 6. Predictive saccade target selection in SC, concentric search task. $\boldsymbol{A}$, Trials from a concentric conjunction search task used to examine single-fixation (black) and multiple-fixation (red) selection. TinRF, Target in RF (solid outlines); DinRF, Distracter in RF (dashed outlines). B, Example SC sensorimotor neuron activity in single-fixation (top) and multiple-fixation (bottom) trials. C, DT distributions in single-fixation (black) and multiple-fixation (red) trials.

A

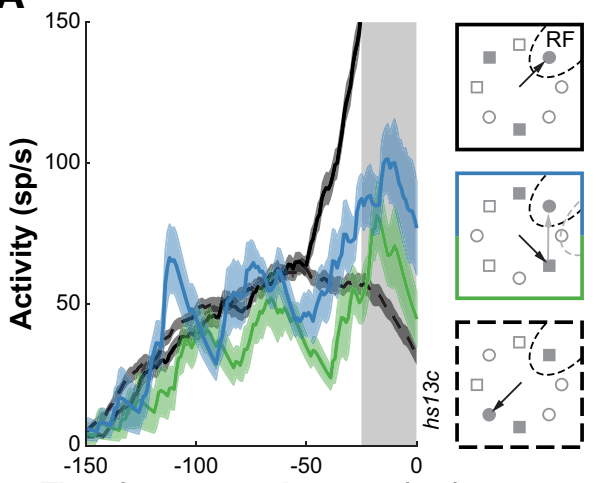

Time from saccade onset (ms)
B

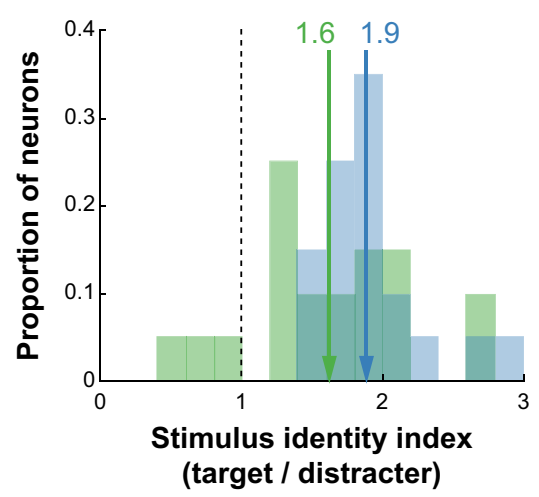

C

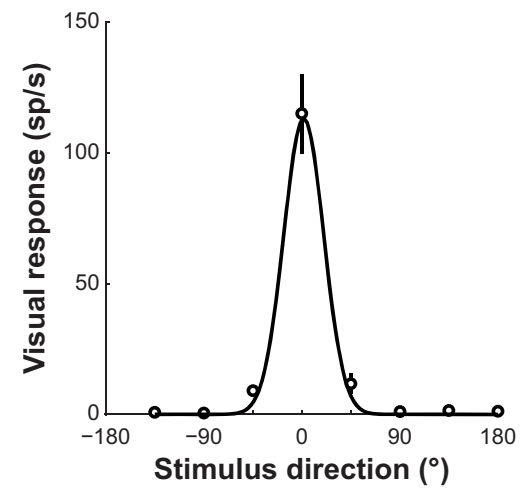

Figure 7. $A$, Example SC sensorimotor neuron activity in a concentric search task. Target-related activity when the monkey makes an initial saccade away from the RF but correctly foveates the target after a second saccade for short (blue) and long (green) intervening fixation durations. Distracter-related activity when the monkey makes a correct saccade to the target away from the RF (dashed black) and target-related activity when the monkey makes a correct saccade to the target in the RF (solid black). Data are aligned to the onset of the first saccade. Gray bar, Epoch of analysis (25 ms before saccades). $\boldsymbol{B}$, Stimulus identity index (target-related/distracter-related activity) for short (blue) and long (green) fixation duration trials. Means of the distributions are indicated. $\boldsymbol{C}$, Visual response tuning of the example neuron in $\boldsymbol{A}$ as determined using the concentric detection task. The magnitude of the visual responses was fit with a Gaussian function.

view that the processing of at least two saccades can occur in parallel (Viviani and Swensson, 1982; Hooge and Erkelens, 1996; Theeuwes et al., 1998; McPeek et al., 2000; McPeek and Keller, 2001; see also Sommer, 1997; Findlay et al., 2001; Godijn and Theeuwes, 2002). Moreover, visual information presented before the first saccade has been shown to be correlated with the outcome of the second saccade, suggesting that information accumulates for the second saccade before the onset of the first saccade (Caspi et al., 2004). Indeed, the processing of visual information by temporal cortical neurons has been shown to begin before the fixation of the target in a complex search task (Sheinberg and Logothetis, 2001). Our current findings complement this literature by showing how the neuronal selection of a subsequent saccade target can occur before it is brought into the RF of a neuron. This parallel selection of saccade targets is accompanied by a process in which visual information is accumulated across saccades, as evidenced by earlier DTs in sessions with more saccades and shorter fixation durations just before target foveation. These findings suggest that, with each fixation, the evidence for the target location grows as the visual salience map is updated.
A substantial body of literature has described how the selection of the first saccade goal in response to a search display occurs across a network of structures that form a distributed visual salience map. These previous visual search studies have established how neurons in area LIP (Ipata et al., 2006; Thomas and Paré, 2007), FEF (Thompson et al., 1996, 2005; Sato et al., 2001), and SC (Ottes et al., 1987; McPeek and Keller, 2002a; Shen and Paré, 2007; Shen et al., 2011) select the saccade goal in advance of saccades. Neurons are consistently reported to have indiscriminate visual responses to both the target and distracter that occur with a latency of 40-60 ms (but see Buschman and Miller, 2007; Premereur et al., 2011). The target-related activity then increases while the distracter-related activity does not, resulting in reliable discriminating activity after $\sim 100-150 \mathrm{~ms}$ (Schall et al., 2007; Shen et al., 2011). This DT corresponds to $\sim 50-70 \mathrm{~ms}$ before saccades.

Only a few studies have extended this approach to examine the saccade selection process when there is more than a single saccade. McPeek and Keller (2002b) showed that, in response to the presentation of the search display, SC neurons have increased activity for a target that will be foveated after a second saccade if 
the intervening fixation is short. This observation suggests that the target representation remained competitive for selection even after an initial erroneous saccade. However, part of this enhancement could also have been attributable to the representation of target identity separate from the saccade goal (Shen and Paré, 2007). Indeed, we showed here using a conjunction search task how even the target-related activity in two-saccade trials having the longest fixation durations was still enhanced compared with distracter-related activity. Other studies examined the activity leading up to the selection of the second saccade rather than the first. For example, Murthy et al. (2007) used a feature search task in which the target occasionally jumped to a new location during saccade planning. On trials in which monkeys made a corrective saccade to the new target location, discriminating activity of FEF neurons was found to occur earlier $(\sim 40-60 \mathrm{~ms}$ after fixation onset) than on successful single-saccade trials. Similarly, recent studies using visual search of natural scenes (Phillips and Segraves, 2010) and dense grid displays (Zhou and Desimone, 2011) reported how selective FEF activity occurred around the time of their visually evoked responses ( $\sim 50 \mathrm{~ms}$ after fixation onset). However, these studies either did not entirely control the placement of the stimulus within the RF of the neuron (Murthy et al., 2007; Zhou and Desimone, 2011) or did not control for the visual stimulation of the neuron across fixations (Phillips and Segraves, 2010). Related to these search data are observations of LIP neurons during a task in which the visual display remained on throughout a session (Gottlieb et al., 1998). Monkeys were trained to shift their eyes so that one of the stable stimuli fell in the $\mathrm{RF}$ of a neuron before foveating the cued stimulus. LIP neurons modulated their activity to signal the location of a relevant stimulus in advance of the saccade that brought the stimulus into the RF. The study we present here adds to these previous observations by quantifying the time course of saccade target selection during sequences of fixations and providing evidence for predictive selection in a structure that more closely affects visual behavior because of its direct outputs to the saccade-generating system (Rodgers et al., 2006).

The relationship between the selection of a saccade goal and the programming of the movement itself has been shown to be dissociated in FEF (Thompson et al., 1996), as well as for some neurons in SC (McPeek and Keller, 2002a). Therefore, the DT/RT slopes of these neurons tend toward 0 , such that saccade latencies cannot be predicted by DTs. In the present study, saccade latencies were predicted by DTs for both single- and multiple-saccade trials, because DT/RT slopes were distributed around 1. We showed previously in a large SC neuronal sample how DT/RT slopes were unimodally distributed around 1 when the search task was unconstrained, suggesting that in natural situations-as in the present multiple-fixation task-visual processing of the next target is not distinct from the selection of the target itself (Shen et al., 2011; see also Ipata et al., 2006; Thomas and Paré, 2007). In the current study, however, the time difference between neuronal discrimination and saccade initiation in these two types of fixations suggests that the process of saccade target selection is distinct from saccade programming. This is consistent with the view that a selection threshold exists separately from the saccade trigger threshold (Shen and Paré, 2007). The observation that the selection of the subsequent saccade target occurred nearly $90 \mathrm{~ms}$ in advance of saccade initiation suggests that there is ample time for that saccade to be countermanded. In other words, there is not necessarily a commitment of a saccade program to the selected item.
Predictive neuronal activity for a stimulus about to be brought into the RF has been reported in SC (Walker et al., 1995), FEF (Umeno and Goldberg, 1997), and area LIP (Duhamel et al., 1992). In these studies, a single visual stimulus is displayed, and the monkey is instructed to shift its eyes to a location that will align the RF with the stimulus once the saccade is made. This activity has been interpreted to be a possible neural substrate for perceptual stability, in which visual RFs (and therefore visual stimuli within them) are "remapped" based on an efference copy of the movement program to account for the displacement of those objects once the eyes have moved (Sommer and Wurtz, 2008). However, evidence in favor of this account has been difficult to obtain. Reports of "change blindness" wherein significant changes to a visual scene remain undetected across saccades (Henderson and Hollingworth, 1999) and limited memory for visual objects across saccades (Irwin and Andrews, 1996) put into question whether spatial remapping serves to stabilize visual perception. Observations that saccade targets (i.e., visited locations) are retained across saccades (Beck et al., 2006) and the presence of remapping activity in visual areas within the dorsal but not ventral stream may instead suggest that predictive activity plays a supporting role in action selection rather than perception (Bays and Husain, 2007). Indeed, if the early increase in activity were attributable to the perceptual remapping of the RF, an increase should occur for both target and distracter stimuli. Instead, we observed that the early modulation in activity was associated only with the stimulus that would become the next saccade target (Fig. $4 B$ ). This finding is supported by a recent behavioral study that suggested how multiple movement programs, rather than retinotopic perceptual locations, are planned in parallel and updated at the end of each saccade (Quaia et al., 2010). Whether perceptual remapping also occurs cannot be determined from our data because there is a stimulus in the RF of a neuron on every fixation. Even so, its contribution to our task may not be significant because remapping activity has been shown to be diminished when tested in less impoverished environments (Churan et al., 2011). The affect of remapping activity in more naturalistic environments has yet to be fully understood.

We extended our understanding of selection mechanisms beyond the first saccade and showed how selection mechanisms are substantially different for subsequent saccade targets. In addition to an enhanced representation for target identity, the processing of time-varying signals on the visual salience map occurs in parallel to support efficient sequences of saccades.

\section{References}

Bahill AT, Bahill KA, Clark MR, Stark L (1975) Closely spaced saccades. Invest Ophthalmol 14:317-321. Medline

Baldauf D, Deubel H (2008) Properties of attentional selection during the preparation of sequential saccades. Exp Brain Res 184:411-425. CrossRef Medline

Bays PM, Husain M (2007) Spatial remapping of the visual world across saccades. Neuroreport 18:1207-1213. CrossRef Medline

Beck MR, Peterson MS, Vomela M (2006) Memory for where, but not what, is used during visual search. J Exp Psychol Hum Percept Perform 32:235250. CrossRef Medline

Becker W, Jürgens R (1979) An analysis of the saccadic system by means of double step stimuli. Vision Res 19:967-983. CrossRef Medline

Bichot NP, Rossi AF, Desimone R (2005) Parallel and serial neural mechanisms for visual search in macaque area V4. Science 308:529-534. CrossRef Medline

Buschman TJ, Miller EK (2007) Top-down versus bottom-up control of attention in the prefrontal and posterior parietal cortices. Science 315: 1860-1862. CrossRef Medline

Caspi A, Beutter BR, Eckstein MP (2004) The time course of visual infor- 
mation accrual guiding eye movement decisions. Proc Natl Acad Sci U S A 101:13086-13090. CrossRef Medline

Churan J, Guitton D, Pack CC (2011) Context dependence of receptive field remapping in superior colliculus. J Neurophysiol 106:1862-1874. CrossRef Medline

De Vries JP, Hooge IT, Verstraten FAJ (2014) Saccades toward the target are planned as sequences rather than as single steps. Psychol Sci 25:215-223. CrossRef Medline

Duhamel JR, Colby CL, Goldberg ME (1992) The updating of the representation of visual space in parietal cortex by intended eye movements. Science 255:90-92. CrossRef Medline

Findlay JM, Brown V, Gilchrist ID (2001) Saccade target selection in visual search: the effect of information from the previous fixation. Vision Res 41:87-95. CrossRef Medline

Gersch TM, Kowler E, Schnitzer BS, Dosher BA (2009) Attention during sequences of saccades along marked and memorized paths. Vision Res 49:1256-1266. CrossRef Medline

Godijn R, Theeuwes J (2002) Programming of endogenous and exogenous saccades: evidence for a competitive integration model. J Exp Psychol Hum Percept Perform 28:1039-1054. CrossRef Medline

Godijn R, Theeuwes J (2003) Parallel allocation of attention prior to the execution of saccade sequences. J Exp Psychol Hum Percept Perform 29:882-896. CrossRef Medline

Gottlieb JP, Kusunoki M, Goldberg ME (1998) The representation of visual salience in monkey parietal cortex. Nature 391:481-484. CrossRef Medline

Henderson JM (2003) Human gaze control during real-world scene perception. Trends Cogn Sci 7:498-504. CrossRef Medline

Henderson JM, Hollingworth A (1999) High-level scene perception. Annu Rev Psychol 50:243-271. CrossRef Medline

Hooge IT, Erkelens CJ (1996) Control of fixation duration in a simple search task. Percept Psychophys 58:969-976. CrossRef Medline

Ipata AE, Gee AL, Goldberg ME, Bisley JW (2006) Activity in the lateral intraparietal area predicts the goal and latency of saccades in a freeviewing visual search task. J Neurosci 26:3656-3661. CrossRef Medline

Irwin DE, Andrews RV (1996) Integration and accumulation of information across saccadic eye movements. In: Attention and performance XVI: information integration in perception and communication (Inui $\mathrm{T}$, McClelland JL, eds), pp 125-156. Cambridge, MA: Massachusetts Institute of Technology.

Kotowicz A, Rutishauser U, Koch C (2010) Time course of target recognition in visual search. Front Hum Neurosci 4:31. CrossRef Medline

McPeek RM, Keller EL (2001) Short-term priming, concurrent processing, and saccade curvature during a target selection task in the monkey. Vision Res 41:785-800. CrossRef Medline

McPeek RM, Keller EL (2002a) Saccade target selection in the superior colliculus during a visual search task. J Neurophysiol 88:2019-2034. Medline

McPeek RM, Keller EL (2002b) Superior colliculus activity related to concurrent processing of saccade goals in a visual search task. J Neurophysiol 87:1805-1815. Medline

McPeek RM, Skavenski AA, Nakayama K (2000) Concurrent processing of saccades in visual search. Vision Res 40:2499-2516. CrossRef Medline

Motter BC, Belky EJ (1998) The guidance of eye movements during active visual search. Vision Res 38:1805-1815. CrossRef Medline

Murthy A, Ray S, Shorter SM, Priddy EG, Schall JD, Thompson KG (2007) Frontal eye field contributions to rapid corrective saccades. J Neurophysiol 97:1457-1469. Medline

Nothdurft HC, Pigarev IN, Kastner S (2009) Overt and covert visual search in primates: reaction times and gaze shift strategies. J Integr Neurosci 8:137-174. CrossRef Medline

Ottes FP, Van Gisbergen JA, Eggermont JJ (1987) Collicular involvement in a saccadic colour discrimination task. Exp Brain Res 66:465-478. CrossRef Medline

Paré M, Wurtz RH (2001) Progression in neuronal processing for saccadic eye movements from parietal cortex area lip to superior colliculus. J Neurophysiol 85:2545-2562. Medline

Phillips AN, Segraves MA (2010) Predictive activity in macaque frontal eye field neurons during natural scene searching. J Neurophysiol 103:12381252. CrossRef Medline

Premereur E, Vanduffel W, Janssen P (2011) Functional heterogeneity of macaque lateral intraparietal neurons. J Neurosci 31:12307-12317. CrossRef Medline

Quaia C, Joiner WM, Fitzgibbon EJ, Optican LM, Smith MA (2010) Eye movement sequence generation in humans: motor or goal updating? J Vis 10:pii: 28. CrossRef Medline

Rayner K (1998) Eye movements in reading and information processing: 20 years of research. Psychol Bull 124:372-422. CrossRef Medline

Rodgers CK, Munoz DP, Scott SH, Paré M (2006) Discharge properties of monkey tectoreticular neurons. J Neurophysiol 95:3502-3511. CrossRef Medline

Sato T, Murthy A, Thompson KG, Schall JD (2001) Search efficiency but not response interference affects visual selection in frontal eye field. Neuron 30:583-591. CrossRef Medline

Schall JD, Paré M, Woodman GF (2007) Comment on “Top-down versus bottom-up control of attention in the prefrontal and posterior parietal cortices." Science 318:44, author reply 44. CrossRef

Sheinberg DL, Logothetis NK (2001) Noticing familiar objects in real world scenes: the role of temporal cortical neurons in natural vision. J Neurosci 21:1340-1350. Medline

Shen K, Paré M (2006) Guidance of eye movements during visual conjunction search: local and global contextual effects on target discriminability. J Neurophysiol 95:2845-2855. CrossRef Medline

Shen K, Paré M (2007) Neuronal activity in superior colliculus signals both stimulus identity and saccade goals during visual conjunction search. J Vis 7:15.1-13. CrossRef Medline

Shen K, Valero J, Day GS, Paré M (2011) Investigating the role of the superior colliculus in active vision with the visual search paradigm. Eur J Neurosci 33:2003-2016. CrossRef Medline

Sommer MA (1997) The spatial relationship between scanning saccades and express saccades. Vision Res 37:2745-2756. CrossRef Medline

Sommer MA, Wurtz RH (2008) Brain circuits for the internal monitoring of movements. Annu Rev Neurosci 31:317-338. CrossRef Medline

Theeuwes J, Kramer AF, Hahn S, Irwin DE (1998) Our eyes do not always go where we want them to go: capture of the eyes by new objects. Psychol Sci 9:379-395. CrossRef

Thomas NW, Paré M (2007) Temporal processing of saccade targets in parietal cortex area LIP during visual search. J Neurophysiol 97:942-947. CrossRef Medline

Thompson KG, Hanes DP, Bichot NP, Schall JD (1996) Perceptual and motor processing stages identified in the activity of macaque frontal eye field neurons during visual search. J Neurophysiol 76:4040-4055. Medline

Thompson KG, Bichot NP, Sato TR (2005) Frontal eye field activity before visual search errors reveals the integration of bottom-up and top-down salience. J Neurophysiol 93:337-351. Medline

Umeno MM, Goldberg ME (1997) Spatial processing in the monkey frontal eye field. I. Predictive visual responses. J Neurophysiol 78:1373-1383. Medline

Van Essen DC, Newsome WT, Maunsell JH (1984) The visual field representation in striate cortex of the macaque monkey: asymmetries, anisotropies, and individual variability. Vision Res 24:429-448. CrossRef Medline

Van Loon EM, Hooge IT, Van den Berg AV (2002) The timing of sequences of saccades in visual search. Proc Biol Sci 269:1571-1579. CrossRef Medline

Viviani P, Swensson RG (1982) Saccadic eye movements to peripherally discriminated visual targets. J Exp Psychol Hum Percept Perform 8:113126. CrossRef Medline

Walker MF, Fitzgibbon EJ, Goldberg ME (1995) Neurons in the monkey superior colliculus predict the visual result of impending saccadic eye movements. J Neurophysiol 73:1988-2003. Medline

Zhou H, Desimone R (2011) Feature-based attention in the frontal eye field and area V4 during visual search. Neuron 70:1205-1217. CrossRef Medline

Zingale CM, Kowler E (1987) Planning sequences of saccades. Vision Res 27:1327-1341. CrossRef Medline 